\title{
Employee Performance Appraisal System USING FUZZY LOGIC
}

\author{
Adnan Shaout* and Mohamed Khalid Yousif** \\ *The Department of Electrical and Computer Engineering \\ The University of Michigan - Dearborn, MI, USA \\ **Collage of Computer Science and Information Technology \\ Collage of Post Graduate, Sudan University of Science and technology
}

\begin{abstract}
Evaluation of employee performance is an important element in enhancing the quality of the work and improves employees' motivation to perform well. It also presents a basis for upgrading and enhancing of an organization. Periodical employees' performance evaluation in an organization assists management to recognize its strengths and weaknesses.
\end{abstract}

This paper presents a design and implementation of a performance appraisal system using the fuzzy logic. In addition to the normal process of performance evaluation modules, the system contains step by step inference engine processes. These processes demonstrate several calculation details in relations composition and aggregation methods such as min operator, algebraic product, sup-min and sup-product. The system has foundation to add-on analysis module to analyze and report the final result using various similarity measures. MS Access database was used to maintain the data, build the inference logic and develop all setting user interfaces.

\section{KEYWORDS}

Employee Evaluation, Fuzz logic Controller, Performance Appraisal, Performance Criteria, Rating.

\section{INTRODUCTION}

As part of planning and preparation for this paper, a study of fundamental system of performance assessment for employees working at some oil companies in Sudan was carried out. The evaluation scale, criteria elements, relations between these elements, and overall process workflow information were gathered and used to design and develop the employee performance appraisal system presented in this paper.

The paper is organized as follows: the first part (sections II to IV) presents literature review, the research Question/hypothesis/philosophy, and methodology. The second part (sections V to X) contains the detailed system components, overall process workflow, data modeling (entity relationship), recommended parts for future development and conclusion.

\section{LITERATURE REVIEW}

Majority of the occurrences that we encounter on a daily basis involve a certain level of ambiguity and fuzziness in the description of their nature. "Khalid's performance is unsatisfied" $\&$ "The Weather is warm today". These are examples fuzzy expressions. What degree of performance is considered unsatisfied? By how much does performance have be increased to be 
considered excellent, and not unsatisfying? Do we all have the same view about his performance? This type of fuzziness associated with continuous phenomena is common in any field of study.

In the conventional mathematical methods, the logic of these methods is the precise Boolean logic which has two states 1 or 0 . That mean each proposition must either be false or true.

In 1965, Lotfi Zadeh introduced fuzzy logic as means to model and handle uncertainty in natural language [1]. Fuzzy logic describes the qualitative nature aspects of the object while conventional logic systems focus on their quantitative aspects.

Two fuzzy approaches can be used to construct performance appraisal. The first one is conventional fuzzy approach, which evaluates overall rating from many linguistic fuzzy input variables without any intermediate fuzzy reasoning using if-then rules. The conventional approach generates too many rules and it is difficult for the expert to take into account all aspects and formulates rules with accurate weight. Organization may need to weight some factor such as employee safety observation over quantity and employee attitude or any other critical element. In this situation, the whole process will become extremely complicated. Moreover, the functions of designing inference rules needs to use customize high level language instead of using the simple fuzzy toolbox. The second approach defines the relationship between the performance critical elements and accordingly specifies new large groups [2]. Hence performance analysis can be separated into multiple thought process such as 'Quality of work' and 'Quantity of work'. These groups are used in fuzzy reasoning to determine intermediate parameter 'Work'. Similarly, 'Reliability' and 'Relationship' are used in fuzzy reasoning to determine intermediate parameter person's 'attitude' and then both group 'work' and 'attitude' are combined in second stage to build work-attitude analysis which is then finally combined with regulatory requirement like 'safety' to generate overall performance rating. This process is known as stage-wise fuzzy reasoning where it will be possible \& flexible to give different degree of weight to different performance groups.

The proposed application of multifactorial evaluation was designed to be as a demonstrative example that inspires the application of one of the fuzzy set theory in the multi-criteria performance appraisal system [3]. Accordingly, a performance appraisal system has been developed using performance appraisal criteria from information and communication based company in Malaysia. The system uses multifactorial assessment model in helping top-level management to evaluate their subordinates.

In [4], alternative technique of handling different kinds of vague data was proposed. It is reasoning based on fuzzy models that replicate the way the people meditate and make judgments. As result of evaluation, discrepancy in outcome is observed between classes using traditional non-fuzzy method and the new proposed fuzzy method. As the non-fuzzy traditional methods follow the exact mathematical rules, the assessment with fuzzy logic provides excellent flexibility in the appraisal process. The fuzzy logic was utilized as calculating technique to appraise the student's academic performance.

Performance appraisal is essential for evaluating the employee's contribution to the organization. Most of performance appraisal criteria are based on both quantitative and qualitative elements. The proposed fuzzy assessment methodology [5] specifies substantial assessment parameters and presents system architecture that establishes a reliable assessment standard for smoothing a decision process. It is comprehensive method for managing vagueness inherent in performance appraisal.

Approach based on the fuzzy analytic hierarchy process (FAHP) and balanced scorecard (BSC) was proposed to appraise the performance of IT department in the manufacturing industry in 
Taiwan [6]. In this proposed approach; the financial, customer, internal business process, and learning and growth, and corresponding performance indicators were established as four major perspectives of the BSC and the analytic hierarchy structure. Due to involvement of uncertainty, fuzziness and ambiguity in human decision-making, the FAHP is accepted and utilized to solve this problem. The solution was facilitated by developing a well-organized and efficient FAHP information system. The results provide guidance to IT departments such as "internal business process and customer have higher weightings".

Employee performance assessment is originated to get an insight and understanding of the employee contribution to the organization [7]. The main objectives of performance assessment are to reward an employee who achieves the organizational goals and to determine which goals are not fulfilled, and to maintain plans to make sure they are achieved in future. The analytic hierarchy process (AHP) is used to calculate employee performance based on unquantifiable and subjective criteria such as planning, discipline, thinking, communication, commitment and teamwork. Each criterion has been divided into sub criteria and pairwise assessments are performed. The overall ratings of the employees are acquired based on the results calculated from AHP.

\section{RESEARCH QueSTION/HYPOTHESIS/PHILOSOPHY}

\subsection{Question}

The most important question that will be focused in this paper is how to accurately compute the overall rating of employee performance using the objectives setting \& appraisal method. There are also extra sub-questions which are stated as follows:

1. What are the objective \& subjective critical elements that will be used to measure the employee performance?

2. What is the inference approach that will be utilized to calculate the overall rating according to several critical elements weights?

3. What is the difference between overall rating using traditional evaluation approach and overall rating using fuzzy logic approach?

\subsection{Hypothesis}

The fuzzy set theory offers a suitable solution to handle the subjective and qualitative critical elements of human judgment. Multi hierarchy process can be used to distribute different critical elements weight to generate the overall rating evaluation. The critical elements definition and related distributed weights are based on the assumption that this information is available from human experts in related area.

\subsection{Philosophy}

The philosophy behind the proposed model is to find a mechanism to improve the employee performance by continuous employee evaluation [8]. The output information of this proposed model is producing the following functions:

- Between-person growth: such as Salary increase, promotion and termination.

- Within-person growth: performance response, recognition of employee strengths/weaknesses, and recognition of employee training needs.

- Systems maintenance: development of organization objectives, human resources planning, and recognition of organizational training objectives) 


\section{Methodology}

The Type-1 fuzzy logic was used in this paper. This is a popular computing framework based on the concepts of fuzzy set theory, if-then rules, and fuzzy reasoning. The basic structure of type-1 fuzzy inference system consist of three conceptual components: rule base, data base (defining membership function), and reasoning mechanism as explained in details in the next sections. Also, MS Access database was used to maintain the data, build the inference logic and develop all setting user interfaces.

\section{SYSTEM COMPONENTS}

\subsection{Structure of a fuzzy logic controller}

In this paper we are using the Mamdani model [9] which is one of the most common fuzzy inference techniques. It takes crisp inputs and produces crisp outputs. It performs this depending on user-defined fuzzy rules on user-defined fuzzy variables. The philosophy behind using a Mamdani rule base to model crisp system behavior is that the rules for many systems can be easily described by humans in terms of fuzzy linguistic values. Thus we can effectively model a complex non-linear system, with common-sense rules with fuzzy variables. Figure 1 shows our fuzzy logic controller (FLC) structure. Below are the main steps in this model:

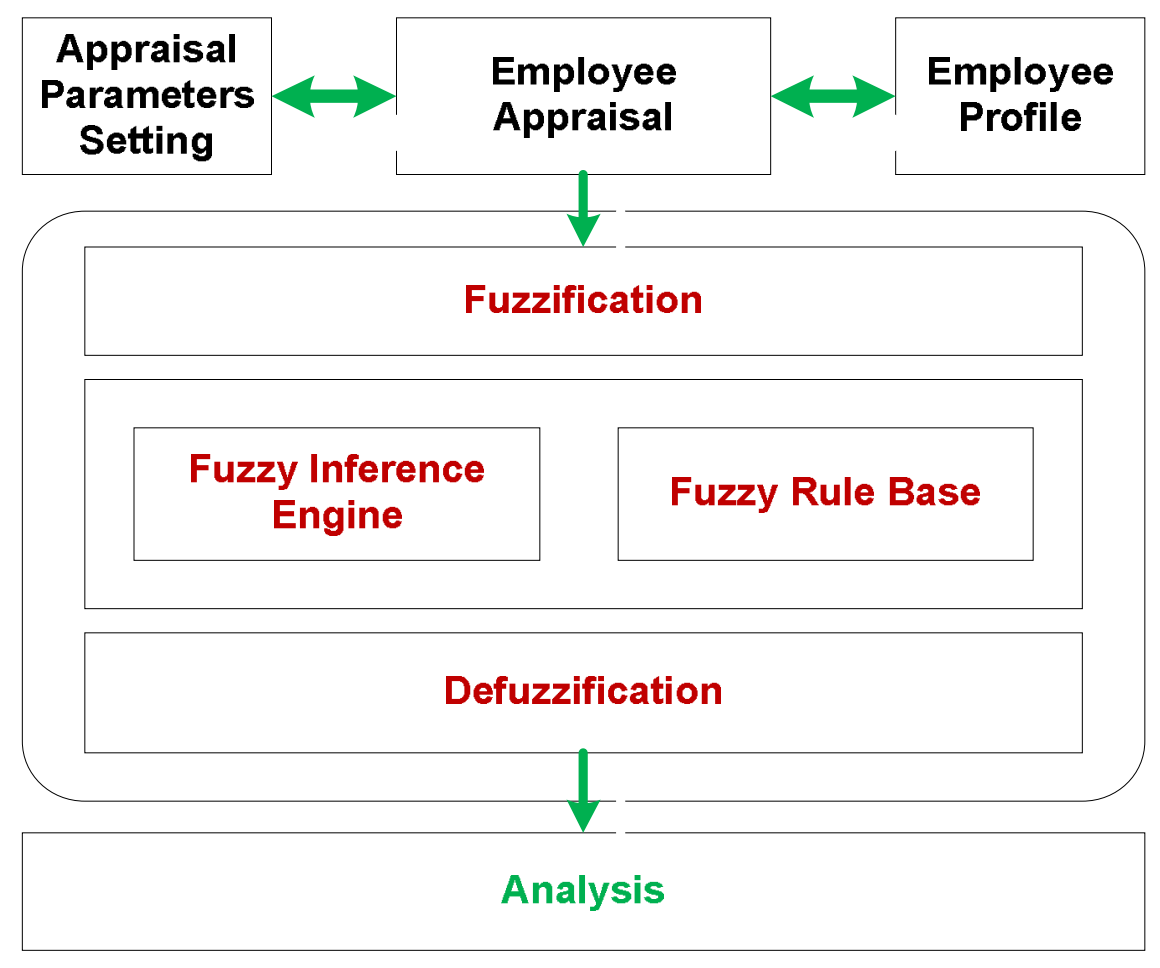

Figure 1: FLC structure

Step 1: Fuzzification

The first step is to take the crisp inputs and determine the degree to which these inputs belong to each of the appropriate fuzzy linguistic values (see Figure 18).

Step 2: Rules evaluation 
The fuzzified inputs are applied to the antecedents of the fuzzy rules. If a given fuzzy rule has multiple antecedents, the fuzzy operator (AND or OR) is used to obtain a single number that represents the result of the antecedent evaluation (see Figure 20).

Step 3: Aggregation of the rule outputs

The membership functions of all rule consequents previously clipped or scaled are combined into a single fuzzy set (see Figures 10 and 11).

Step 4: Defuzzification: The most popular defuzzification method is the centroid technique (see Figure 12).

\subsection{System Components List}

The implemented system shown in figure 2 has the following components:

- Inference System (Compute the output of the Mamdani model)

$\circ$ Compute the Relations using MIN Operator. (method 1)

- Compute the Relations using algebraic product (method 2).

- Compute the outputs using the compositional rule of inference (Inputs o Relation) with Sup-min operator (method 1)

- Compute the outputs using the compositional rule of inference (Inputs x Relation) with Sup-product operator (method 2)

- Compute the final output by aggregate the outputs using Max operator (method 1)

- Compute the final output by aggregate the outputs using the Additive operator (sum) (method 2)

- Compute the final output defuzzification using centroid for both methods $1 \& 2$.

- Performance Criteria Setting

- Criteria

- Criteria type

- Linguistic Variable (Scale)

- Membership function

- FIS Methods Setting (aggregation, defuzzification, etc.)

- Define Functional Rules \& rules Report

- Employee Performance assessment Sheet \& Evaluation Report

- Employee Master data

- Employee Personal data

- Appraiser

- Position

- Nationality

- Position

○ Division 


\section{Process Workflow}

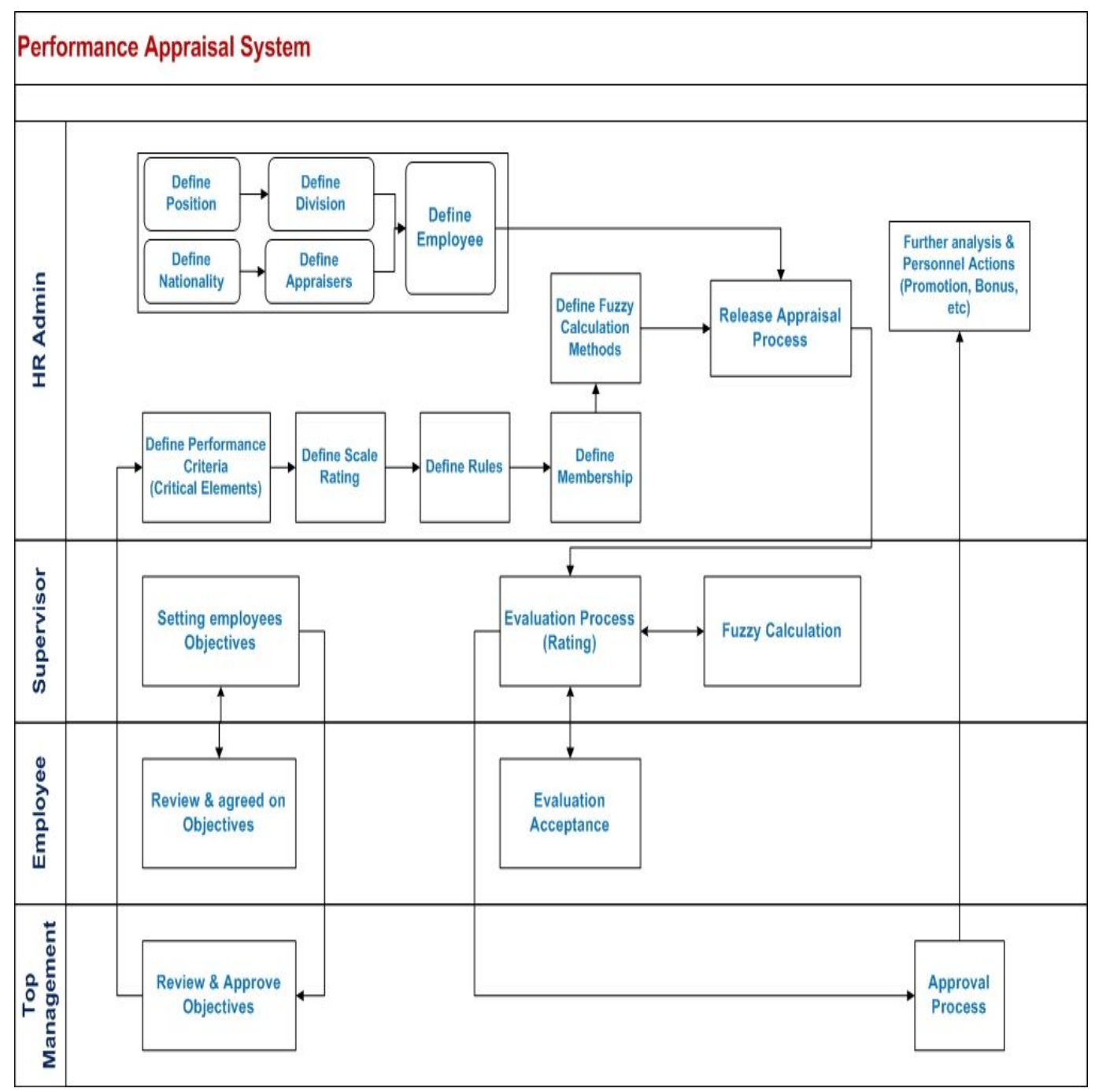

Figure 2. Performance Appraisal System

The swim lanes process mapping technique (cross-functional flow map) is used in this application. The process workflow of performance Appraisal System in figure 2 shows who/where the processes will be performed. Therefore, it's simple to map out the whole process, the roles, responsibilities and the inter dependencies of a given individual or department.

\section{Data Modeling}

Figure 3 describes the general overview of the performance appraisal system application data modeling (entities join relations, etc.). 
International Journal of Computer Science \& Information Technology (IJCSIT) Vol 6, No 4, August 2014

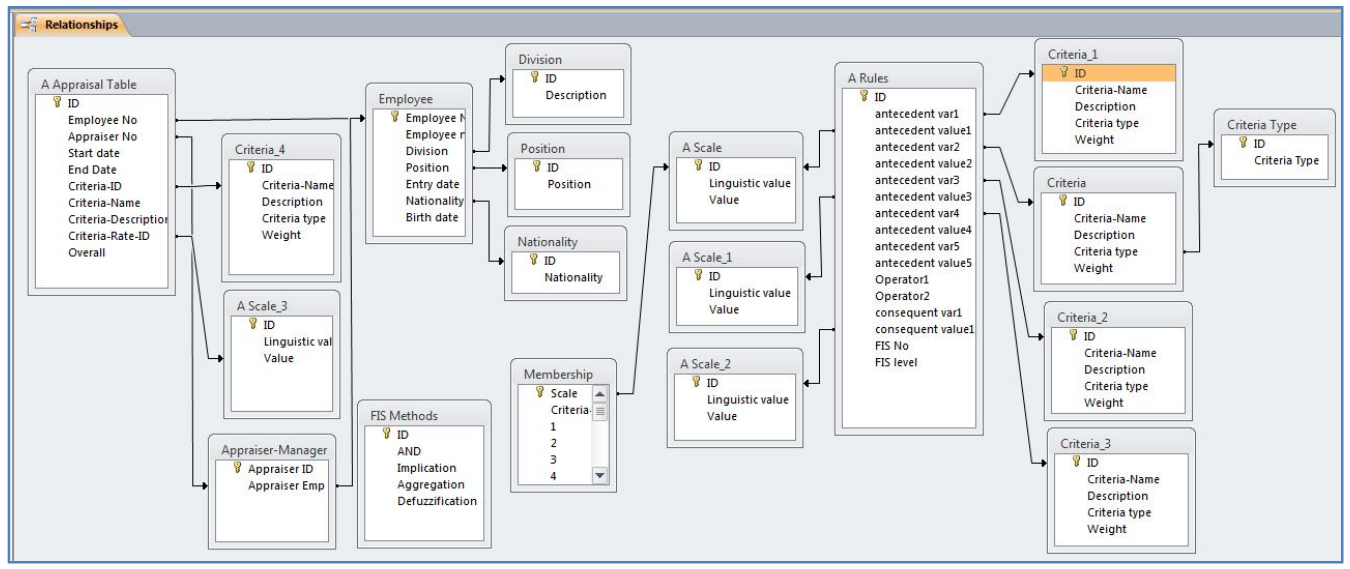

Figure 3. Data Modeling

\section{DETAIL SYSTEM COMPONENTS}

This section demonstrates the application sub programs as shown in figure 4 and related functions. The software implementation for this system application consists of five main modules. Each one of those module contains several applications as follows:

a. Inference Engine/System (Compute the output of the Mamdani model)

b. Performance Criteria Setting

c. Setting Functional Rules \& Rules Report

d. Employee Performance Assessment Sheet \& Evaluation Report

e. Employee Master Data: Performance Criteria Setting

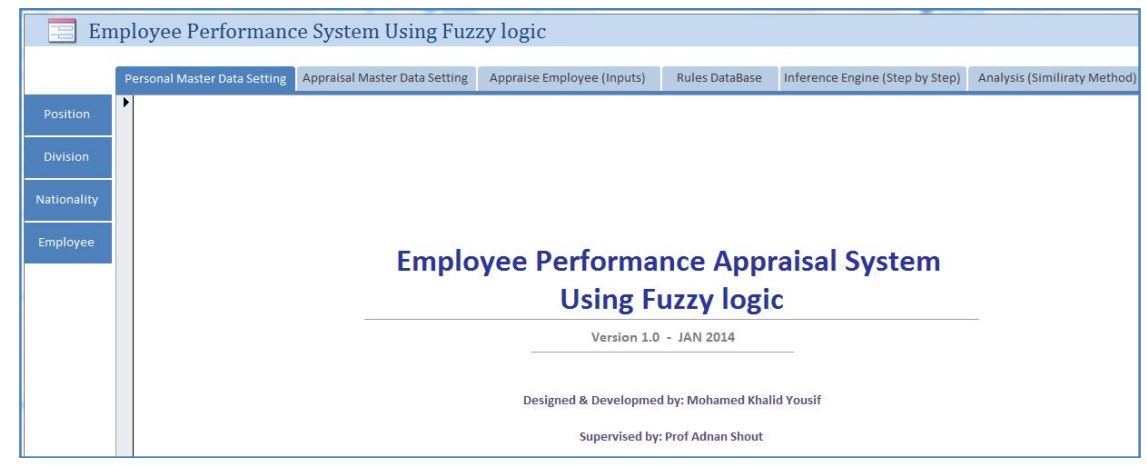

Figure 4. Main Menu

More details will be presented for each one of these modules in the following sections.

\subsection{Inference Engine/System}

It consists of several sub-modules. Each sub-module computes one step in order to get the final result of the Mamdani model. The inference engine module performs the following functions as shown in figure 5 :

i. Compute Relation (Min Operator): This process computes the relations using MIN Operator. (method1, see figure 6 and figure 6.1) or

ii. Compute Relation (Algebraic product): This process computes the relations using algebraic product (method2, see figure 7 and figure 7.1) 
iii. Compute Input (Input o R): This process computes the outputs using the compositional rule of inference (Inputs o Relation) with Sup-min operator (method1, see figure 8) or

iv. Compute Input (Input x R): Compute the outputs using the compositional rule of inference (Inputs x Relation) with Sup-product operator (method2, see figure 9)

v. Aggregation (Max operator): This process calculates the final output by aggregating the outputs using Max operator (method1, see figure 10) or

vi. Aggregation (Additive operator): This process calculates the final output by aggregating the outputs using the Additive operator, the sum. (method2, see figure 11)

vii. Defuzzification: This process computes the final output defuzzification using centroid for both methods (method1 \& method2, see figure 12)

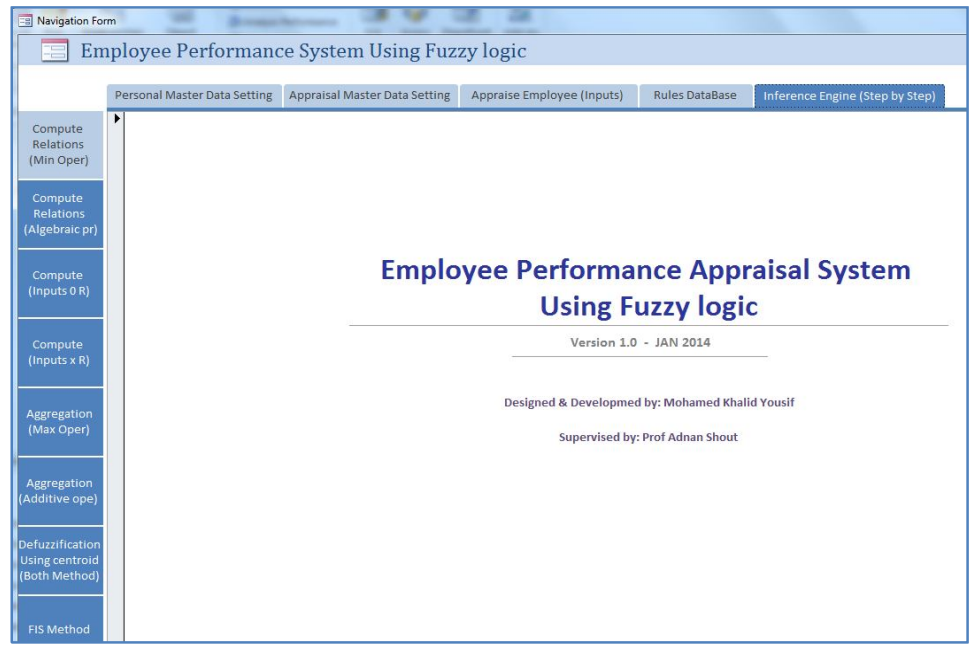

Figure 5. Inference Engine - main menu

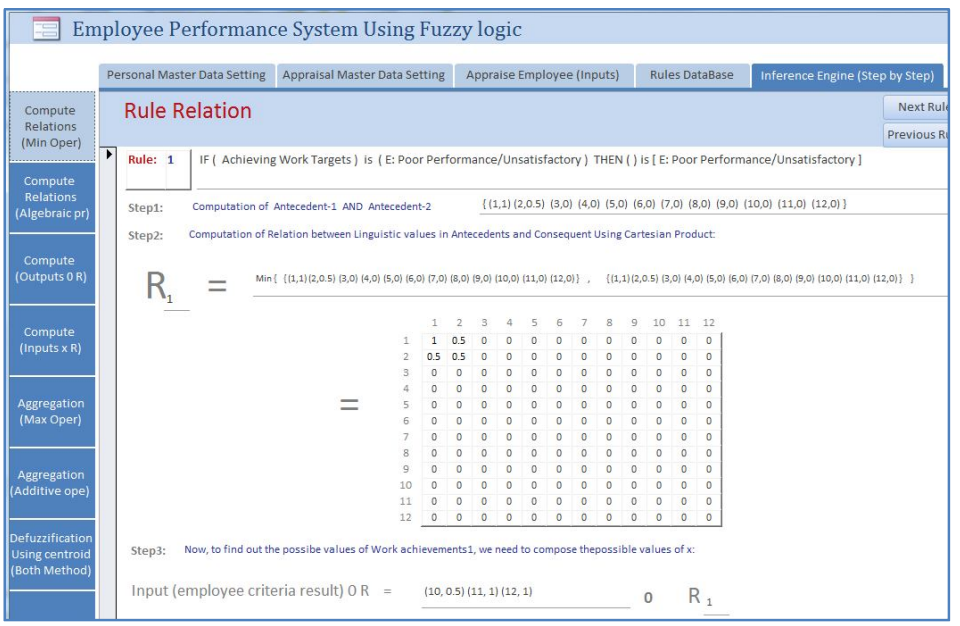

Figure 6. Compute Relation for Rule1 (Min operator)

Figures 6 and 6.1 explain how the software application combine and compute more than one antecedent in rules and how to use this result to compute the relation between linguistic values in antecedents and consequent using the min operator to construct the Cartesian product. Examples 1 and 2 are given below to demonstrate the process of computing relations for rule 1 and rule10 from the fuzzy rule base shown in figure 20. 
International Journal of Computer Science \& Information Technology (IJCSIT) Vol 6, No 4, August 2014

Example 1, for rule 1 that was defined in the rule setting sub-module as shown in figure 20 as follows: If (Achieving Work Target) is (E: Poor Performance/Unsatisfactory) THEN (Work Achievement) is (E: Poor Performance/Unsatisfactory).

Step1: Computation of antecedent-1 AND Antecedent-2 - Since rule1 has only one antecedent with value (E), then the combination of antecedents' part is computed as follows:

$\{(1,1)(2,0.5)(3,0)(4,0) \ldots(12,0)\}$

Step2: Relation Computation (R)

In this step construct the relation between linguistic values in the antecedents and Consequence using Cartesian product (min-max),

Then, the relation for rule $1=$

$\vee(\{(1,1)(2,0.5)(3,0)(4,0)(5,0)(6,0)(7,0)(8,0)(9,0)(10,0)(11,0)(12,0)\} \wedge\{$ $(1,1)(2,0.5)(3,0)(4,0)(5,0)(6,0)(7,0)(8,0)(9,0)(10,0)(11,0)(12,0)\})$

$$
={ }_{2}^{1}\left[\begin{array}{cc}
1 & 2 \\
0.5 & 0.5
\end{array}\right]
$$

Example 2, for rule10 that was defined in the rule setting sub-module as shown in figure 20 as follows: IF (Achieving Work Targets) is (C: Meets Job Requirements-Average Performance) AND (Contributing to teamwork) is (C: Meets Job Requirements-Average Performance) THEN (Work Achievements) is [C: Meets Job Requirements-Average Performance)]

Step1: Computation of antecedent-1 AND antecedent-2 - Since rule1 has two antecedents with value $(\mathrm{C} \& \mathrm{D})$, then the combination of antecedents' part will be computed as follows:

$\{(1,0)(2,0)(3,0)(4,0.5)(5,1)(6,0.5)(7,0)(8,0)(9,0)(10,0)(11,0)(12,0)\}$

Step2: Relation Computation (R)

In this step construct the relation between the computation result of linguistic values in the antecedents and Consequence using Cartesian product (min-max),

Then, the relation for rule $10=$

$\vee(\{(1,0)(2,0)(3,0)(4,0.5)(5,1)(6,0.5)(7,0)(8,0)(9,0)(10,0)(11,0)(12,0)\} \wedge\{(1,0)(2$,

0) $(3,0)(4,0.5)(5,1)(6,0.5)(7,0)(8,0)(9,0)(10,0)(11,0)(12,0)\}=$

$\begin{array}{lccc} & 4 & 5 & 6 \\ 4 \\ 5 \\ 6\end{array}\left[\begin{array}{ccc}0.5 & 0.5 & 0.5 \\ 0.5 & 1 & 0.5 \\ 0.5 & 0.5 & 0.5\end{array}\right]$


International Journal of Computer Science \& Information Technology (IJCSIT) Vol 6, No 4, August 2014

\begin{tabular}{|c|c|c|c|c|c|c|c|c|c|c|c|c|c|c|}
\hline \multirow{14}{*}{$\mathrm{R}_{10}=$} & \multicolumn{9}{|c|}{$\operatorname{Min}\{\{(1,0)(2,0)(3,0)(4,0.5)(5,1)(6,0.5)(7,0)(8,0)(9,0)(10,0)(11,0)(12,0)\}$, } & \multicolumn{5}{|c|}{$(1,0)(2,0)(3,0)(4,0.5)(5,1)(6,0.5)(7,0)(8,0)(9,0)(10,0)(11,0)(12,0)$} \\
\hline & & & 1 & 2 & 3 & 4 & 5 & 6 & 7 & 8 & 9 & 10 & 11 & 12 \\
\hline & & 1 & 0 & 0 & 0 & 0 & 0 & 0 & 0 & 0 & 0 & 0 & 0 & 0 \\
\hline & & 2 & 0 & 0 & 0 & 0 & 0 & 0 & 0 & 0 & 0 & 0 & 0 & 0 \\
\hline & & 3 & 0 & 0 & 0 & 0 & 0 & 0 & 0 & 0 & 0 & 0 & 0 & 0 \\
\hline & & 4 & 0 & 0 & 0 & 0.5 & 0.5 & 0.5 & 0 & 0 & 0 & 0 & 0 & 0 \\
\hline & $=$ & 5 & 0 & 0 & 0 & 0.5 & 1 & 0.5 & 0 & 0 & 0 & 0 & 0 & 0 \\
\hline & & 6 & 0 & 0 & 0 & 0.5 & 0.5 & 0.5 & 0 & 0 & 0 & 0 & 0 & 0 \\
\hline & & 7 & 0 & 0 & 0 & 0 & 0 & 0 & 0 & 0 & 0 & 0 & 0 & 0 \\
\hline & & 8 & 0 & 0 & 0 & 0 & 0 & 0 & 0 & 0 & 0 & 0 & 0 & 0 \\
\hline & & 9 & 0 & 0 & 0 & 0 & 0 & 0 & 0 & 0 & 0 & 0 & 0 & 0 \\
\hline & & 10 & 0 & 0 & 0 & 0 & 0 & 0 & 0 & 0 & 0 & 0 & 0 & 0 \\
\hline & & 11 & 0 & 0 & 0 & 0 & 0 & 0 & 0 & 0 & 0 & 0 & 0 & 0 \\
\hline & & 12 & 0 & 0 & 0 & 0 & 0 & 0 & 0 & 0 & 0 & 0 & 0 & 0 \\
\hline
\end{tabular}

Figure 6.1. Compute Relation for Rule10 (Min oper)

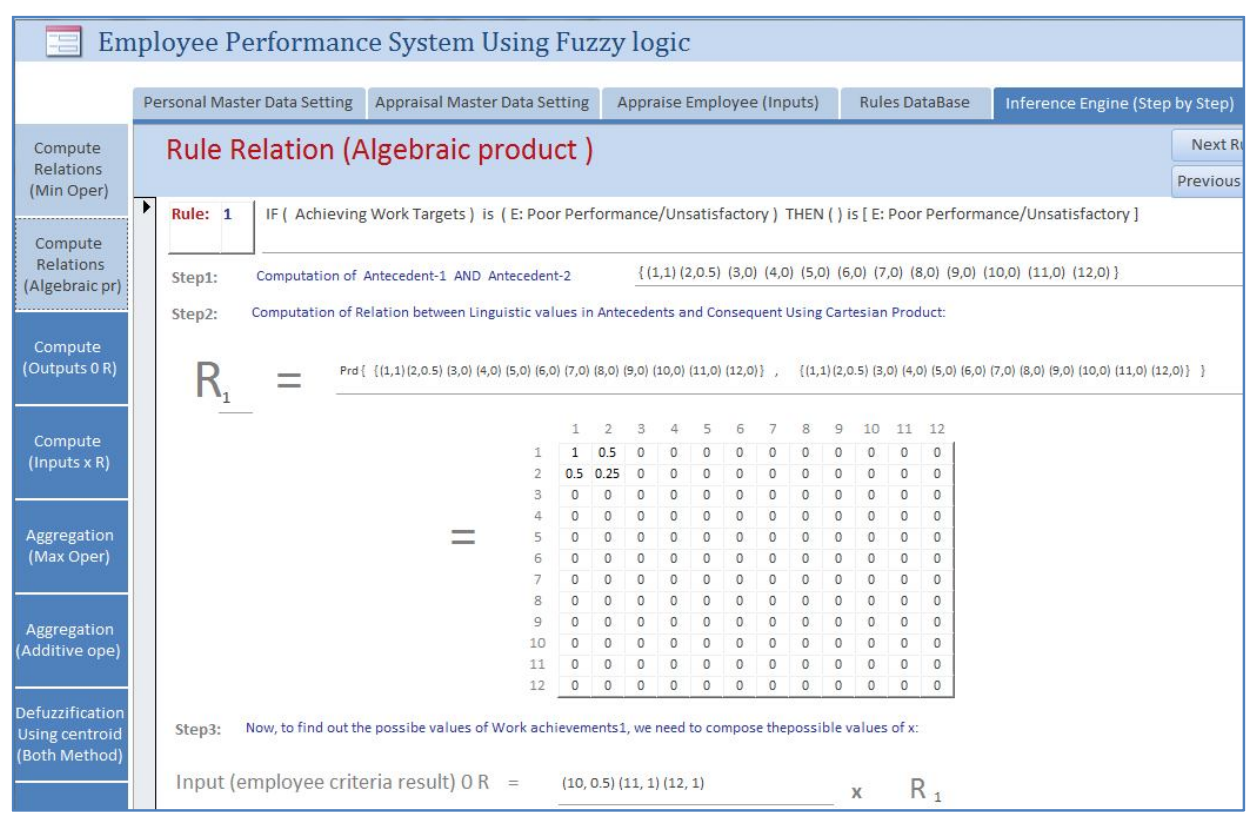

Figure 7. Compute Relation for Rule1 (Algebraic Product)

Figures 7 and 7.1 explain the same function using the algebraic product. 
International Journal of Computer Science \& Information Technology (IJCSIT) Vol 6, No 4, August 2014

\begin{tabular}{|c|c|c|c|c|c|c|c|c|c|c|c|c|}
\hline & 1 & 2 & 3 & 4 & 5 & 6 & 7 & 8 & 9 & 10 & 11 & 12 \\
\hline 1 & 0 & 0 & 0 & 0 & 0 & 0 & 0 & 0 & 0 & 0 & 0 & 0 \\
\hline 2 & 0 & 0 & 0 & 0 & 0 & 0 & 0 & 0 & 0 & 0 & 0 & 0 \\
\hline 3 & 0 & 0 & 0 & 0 & 0 & 0 & 0 & 0 & 0 & 0 & 0 & 0 \\
\hline 4 & 0 & 0 & 0 & 0.25 & 0.5 & 0.25 & 0 & 0 & 0 & 0 & 0 & 0 \\
\hline 5 & 0 & 0 & 0 & 0.5 & 1 & 0.5 & 0 & 0 & 0 & 0 & 0 & 0 \\
\hline 6 & 0 & 0 & 0 & 0.25 & 0.5 & 0.25 & 0 & 0 & 0 & 0 & 0 & 0 \\
\hline 7 & 0 & 0 & 0 & 0 & 0 & 0 & 0 & 0 & 0 & 0 & 0 & 0 \\
\hline 8 & 0 & 0 & 0 & 0 & 0 & 0 & 0 & 0 & 0 & 0 & 0 & 0 \\
\hline 9 & 0 & 0 & 0 & 0 & 0 & 0 & 0 & 0 & 0 & 0 & 0 & 0 \\
\hline 10 & 0 & 0 & 0 & 0 & 0 & 0 & 0 & 0 & 0 & 0 & 0 & 0 \\
\hline 11 & 0 & 0 & 0 & 0 & 0 & 0 & 0 & 0 & 0 & 0 & 0 & 0 \\
\hline 12 & 0 & 0 & 0 & 0 & 0 & 0 & 0 & 0 & 0 & 0 & 0 & 0 \\
\hline
\end{tabular}

Figure 7.1. Compute Relation for Rule10. (Algebraic Product)

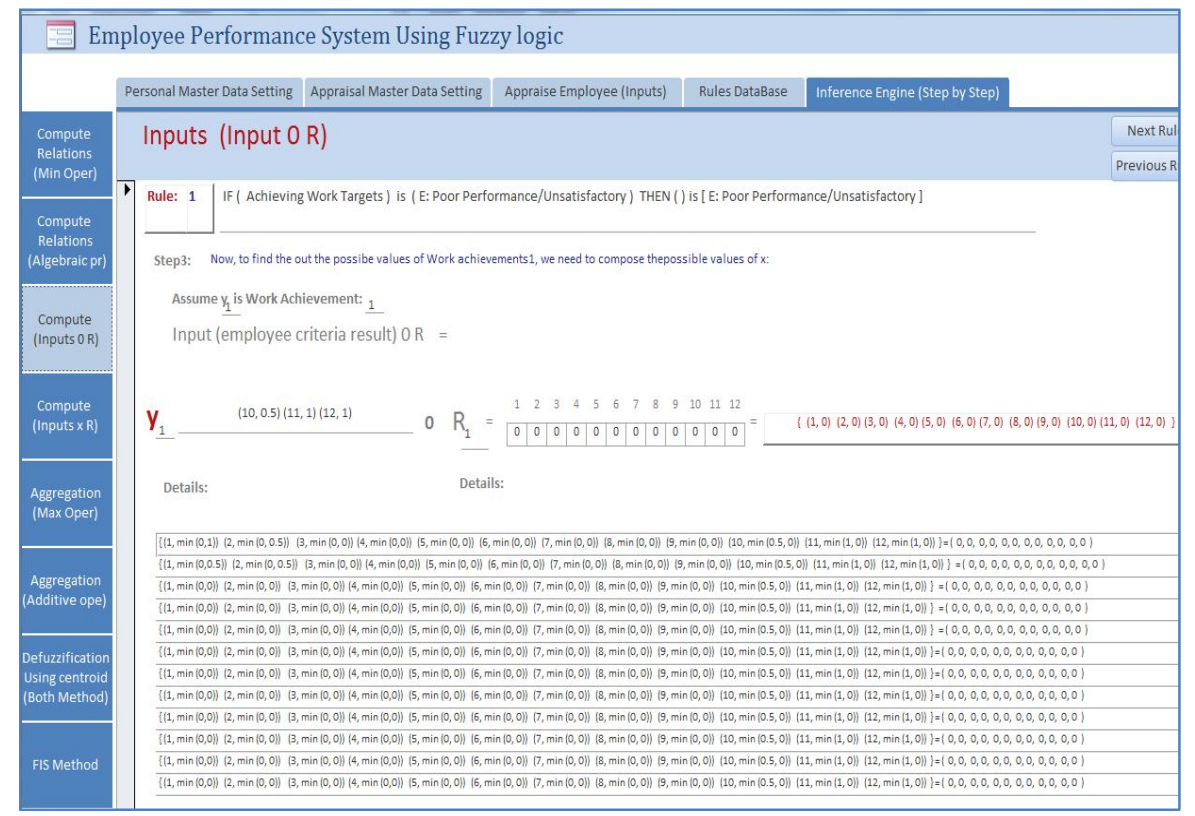

Figure 8. Compute (Input o Relation)

Figure 8 uses the compositional rule of inference with sup-min operator to produce input for each rule (i.e. y1 for rule1, y2 for rule2 etc.) 
International Journal of Computer Science \& Information Technology (IJCSIT) Vol 6, No 4, August 2014

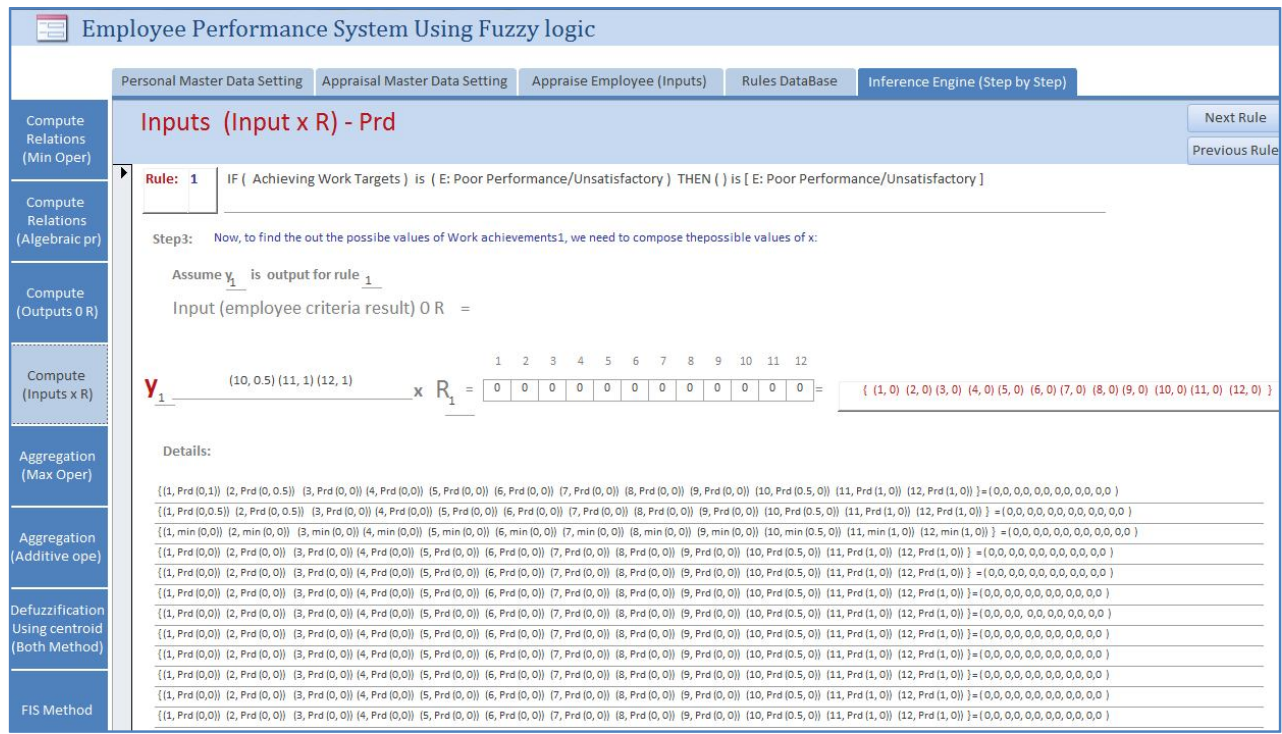

Figure 8. Compute (Input x Relation)

Figure 8 uses the compositional rule of inference with sup-product operator, the output y1, y2, y3 ... y32. From the first rule, second rule, etc.

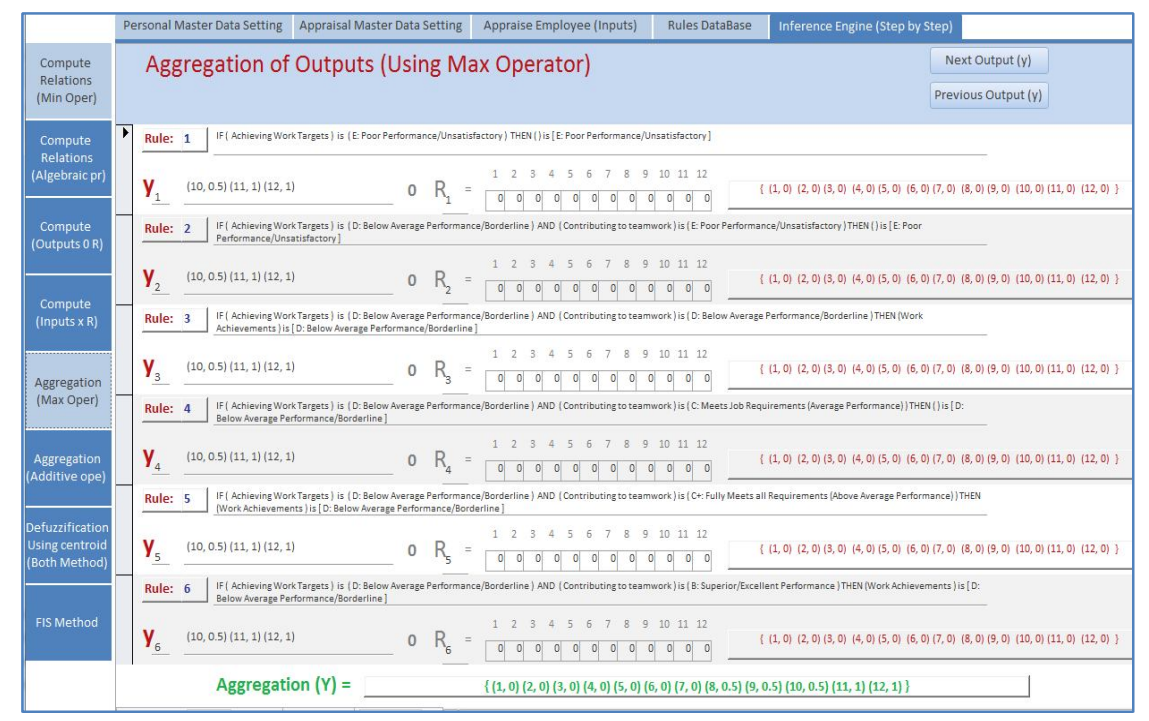

Figure 10. Aggregation (Max Operator)

In figure 10, the application computes the final output for this model by aggregating all the outputs from $\mathrm{y} 1, \mathrm{y} 2 \ldots$ and $\mathrm{y} 32$ using max operator. 
International Journal of Computer Science \& Information Technology (IJCSIT) Vol 6, No 4, August 2014

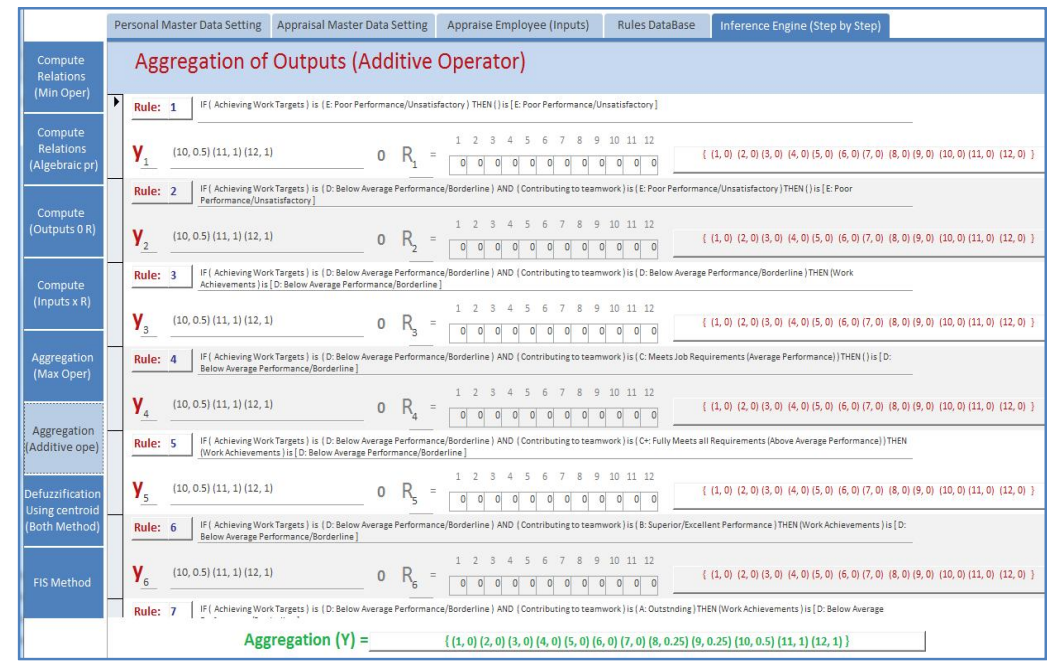

Figure 11. Aggregation (Additive Operator)

Figure 11 explains the final output after aggregation of outputs from (y1, y2... y32) using the additive operator (sum).

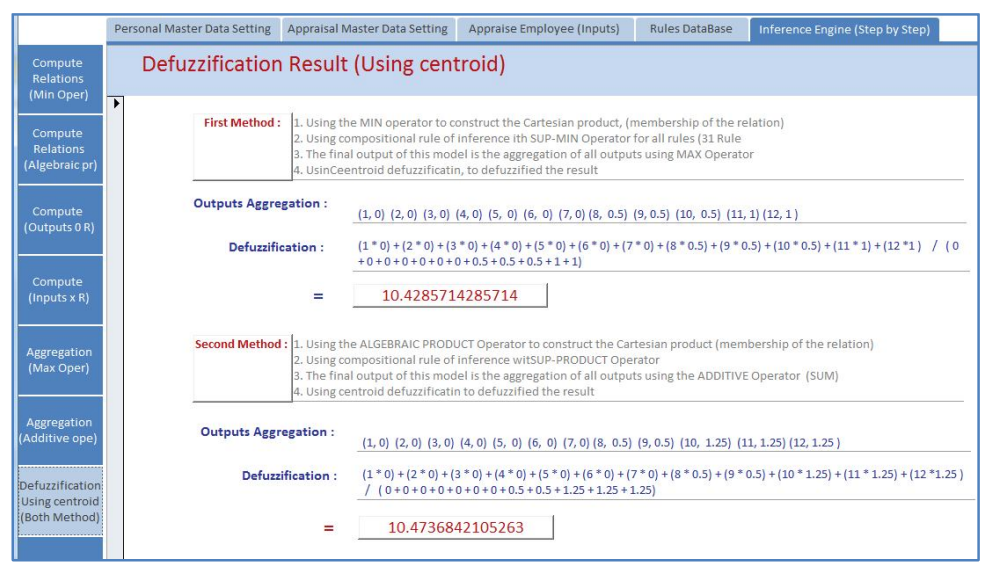

Figure 12. Defuzzificction

Figure 12 shows how the system computes and explains the defuzzification process to get the final crisp result.

The system uses min operator and algebraic product to construct the Cartesian product in method1 and method2, respectively. Also, the system computes the compositional rule of inference with the sup-min operator and sup-product for method1 and method 2 respectively. For aggregation, the system uses the max operator for method1 and additive operator for method2.

\subsection{Performance Criteria Setting}

This module performs the following function as shown in figure 13:
i. Define Appraiser (Figure 14)
ii. Define Criteria Type (Figure 15)
iii. Define Evaluation Criteria (Figure 16) 
International Journal of Computer Science \& Information Technology (IJCSIT) Vol 6, No 4, August 2014

iv. Define Scale (Linguistic Values - Figure 17)

v. Define Membership function (Figure 18)

vi. $\quad$ Define Setting Functional Rules \& rules Report (Figures 19 and 20)

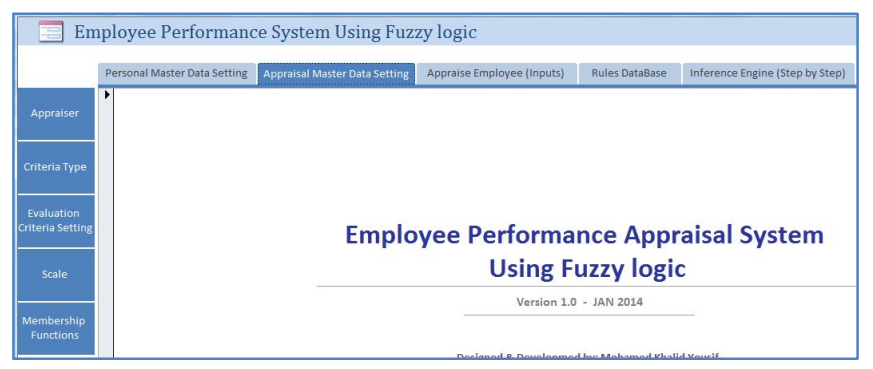

Figure 13. Main Performance Criteria Setting

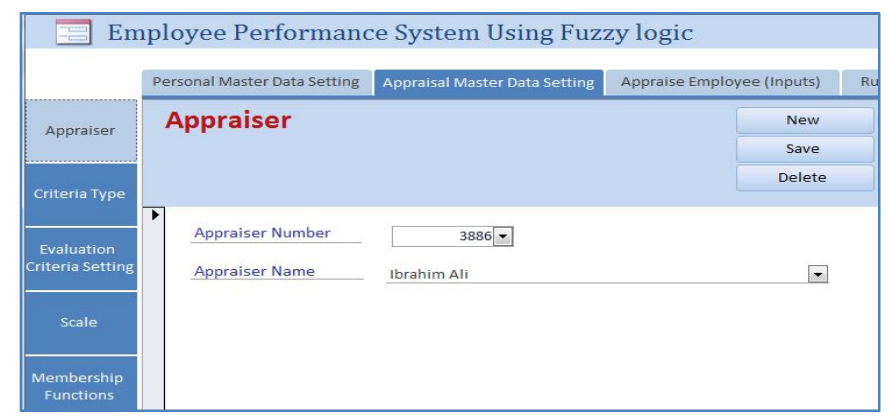

Figure 14. Appraiser

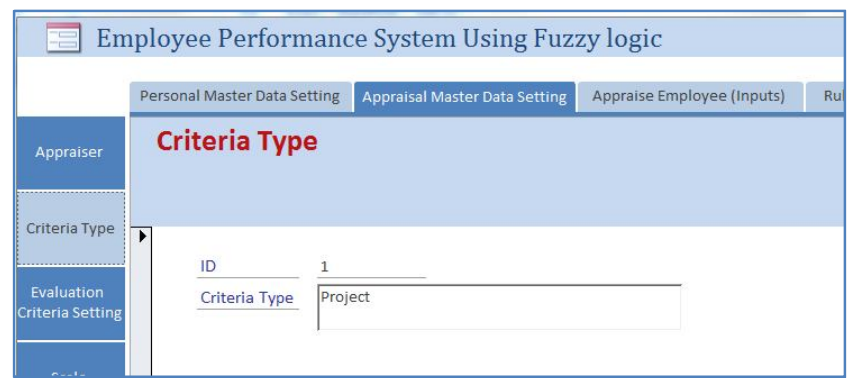

Figure 15. Criteria Type

In this application HR admin will be able to define Criteria type's master data such as projects \& soft skill. Appraisal \& objectives setting is one of the appraisal method uses to evaluate employee where you need to define two types of criteria: the employee objectives/projects for the specific period of time and the general requirements of employee soft skill. Figure 15, enables the HR admin to define the criteria type. 
International Journal of Computer Science \& Information Technology (IJCSIT) Vol 6, No 4, August 2014

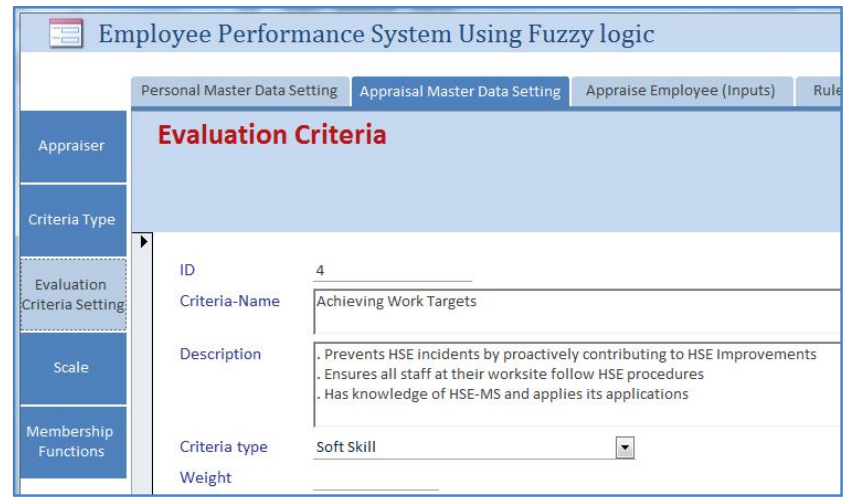

Figure 16. Evaluation Criteria

In this application HR admin will be able to define the both types of criteria: The first type is fixed criteria and use for all employees (soft skill). The second one is related to specific employee annual planned projects, which will be changed every year.

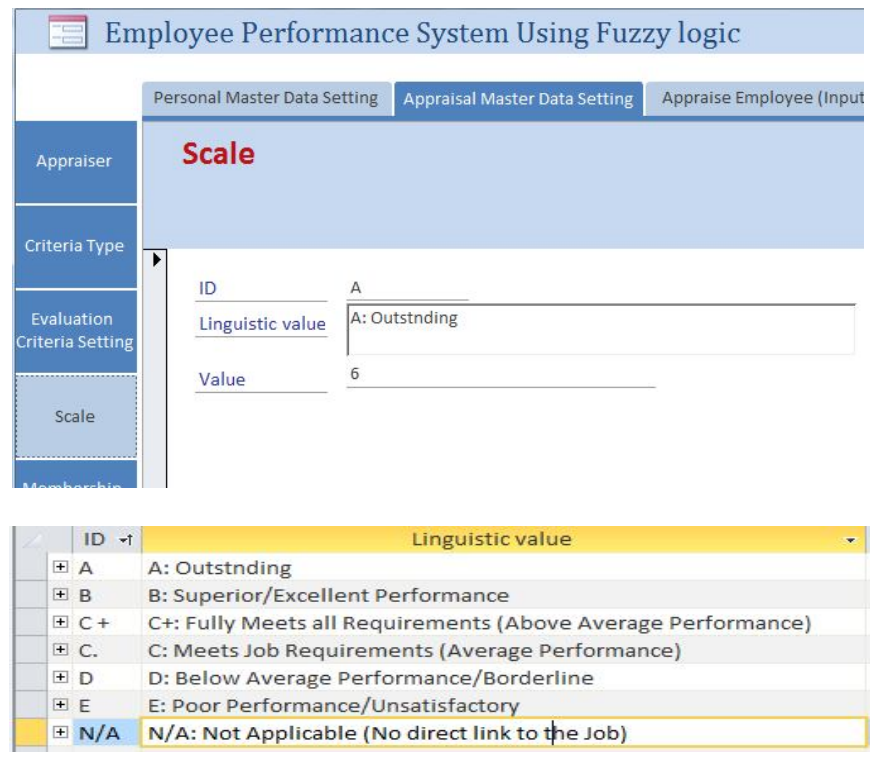

Figure 17. Scale (Linguistic Values)

In this application HR admin will be able to define the scale of the proficiency level which will be used to evaluate the each criteria and the final employee evaluation.

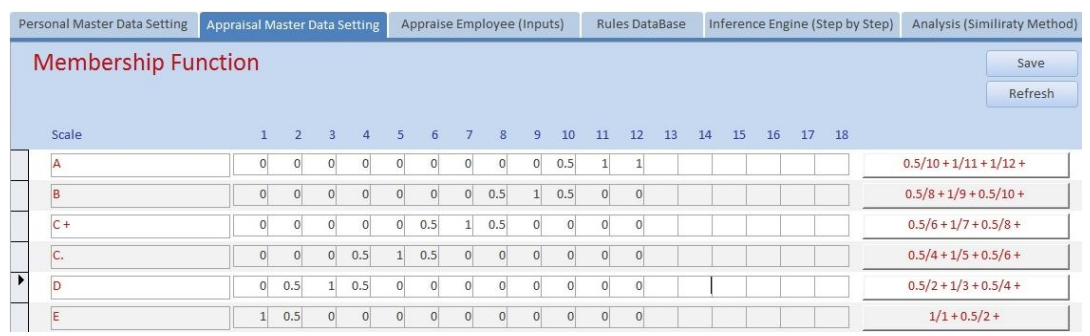


International Journal of Computer Science \& Information Technology (IJCSIT) Vol 6, No 4, August 2014

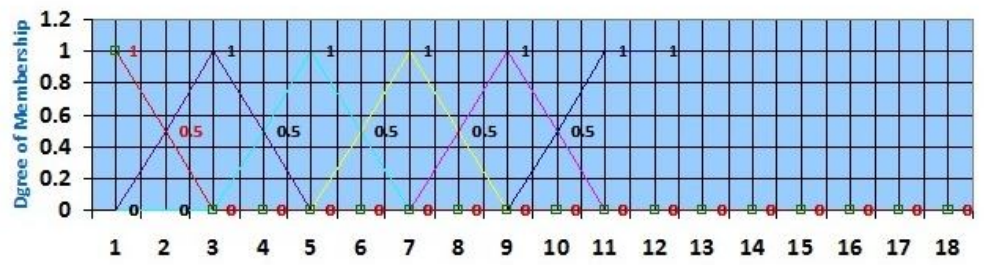

Figure 18. Membership functions

This part of application allows you to set the degree of membership for each linguistic value. Also, it generates the required membership degree graph for all linguistic values as shown in Figure 18.

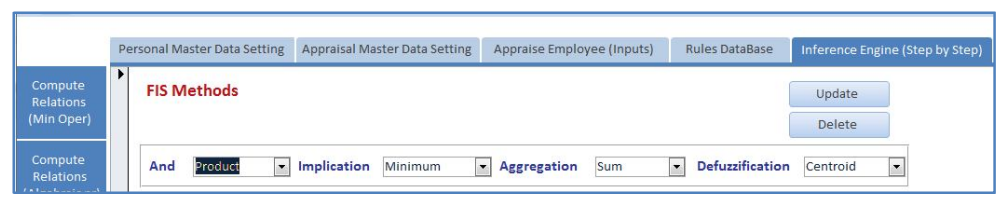

Figure 19. FIS Methods Setting (aggregation, defuzzification, etc.)

Fuzzy inference system (FIS) method window in figure 19 allows you to set the calculation methods.

\subsection{Setting Functional Rules \& Rules Report}

The fuzzy inference engine (algorithm) combines fuzzy IF-THEN rules into a mapping from fuzzy sets in the input space $\mathrm{X}$ to fuzzy sets in the output space $\mathrm{Y}$ based on fuzzy logic principles. In this window, HR Admin will be able to maintain all fuzzy related rules that were defined by an expert. In our design, we used stage-wise fuzzy reasoning (group related critical factors). For example; the element like 'Contributing to teamwork' \& 'Achieving Work Targets' are combined to reflect 'Work Achievement'.

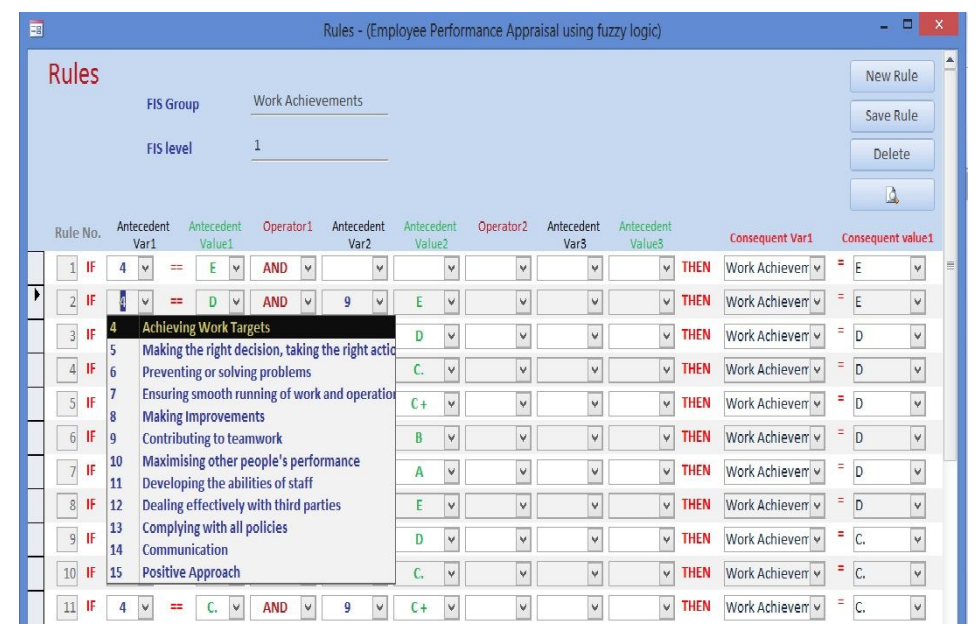


International Journal of Computer Science \& Information Technology (IJCSIT) Vol 6, No 4, August 2014

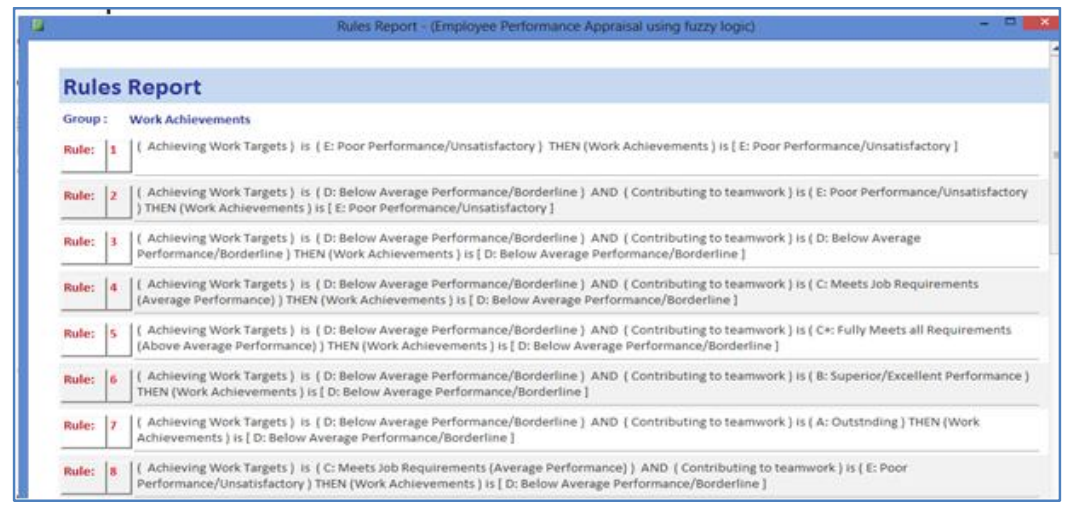

Figure 20. Rules setting main menu and Rules report

\subsection{Employee Performance Assessment Sheet \& Evaluation Report}

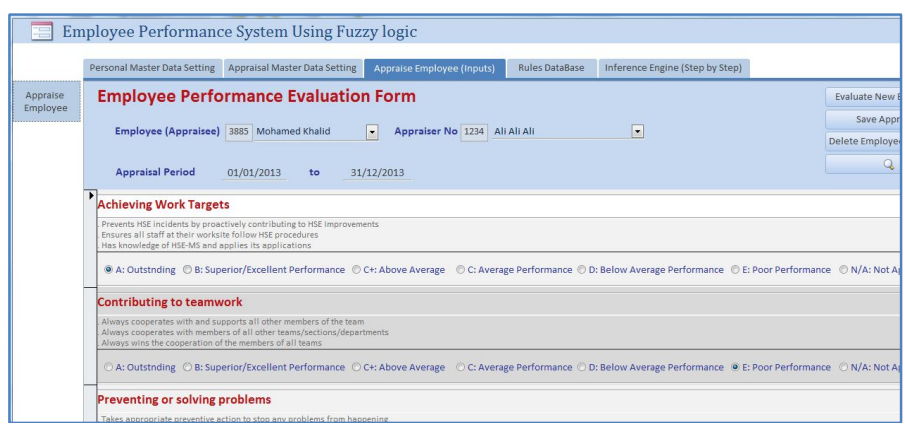

Figure 21. Employee Performance assessment Sheet

Figure 21 shows the module that allows appraisers (managers/supervisors) to evaluate their subordinates as per agreed criteria and setting planned objectives. Figure 22 shows a sample appraisal report for an employee.

\begin{tabular}{|c|c|c|c|c|c|c|}
\hline \multicolumn{7}{|c|}{ Employee Appraisal (Employee wise) } \\
\hline Employee No & \multicolumn{4}{|c|}{3885 Mohamed Khalid } & \multirow{2}{*}{$\begin{array}{l}\text { Position } \\
\text { Description }\end{array}$} & \multirow{2}{*}{$\begin{array}{l}\text { SAP HR Support Team Lead } \\
\text { Information Systems \& Technology }\end{array}$} \\
\hline Appraisal Period & \multicolumn{4}{|c|}{$1 / 1 / 2013$ to } & & \\
\hline Appraiser/Manager & \multicolumn{4}{|c|}{1234 Ali Ali Ali } & & \\
\hline \multicolumn{4}{|l|}{ Positive Approach } & Sott skill & \multicolumn{2}{|c|}{ A: Outstnding } \\
\hline \multicolumn{7}{|c|}{ 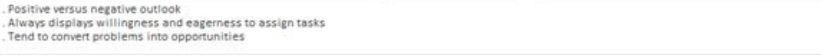 } \\
\hline \multicolumn{4}{|l|}{ Communication } & sof sxili & \multicolumn{2}{|c|}{ A: Outstnding } \\
\hline \multicolumn{7}{|c|}{ 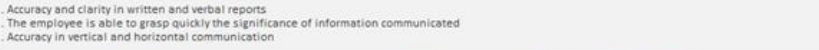 } \\
\hline \multicolumn{4}{|c|}{ Complying with all policies } & Solt skill & \multicolumn{2}{|c|}{ B: Superior/Excellent Performance } \\
\hline \multicolumn{7}{|c|}{ 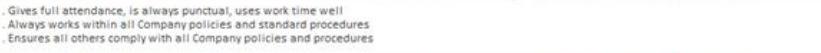 } \\
\hline \multicolumn{4}{|c|}{ Dealing effectively with third parties } & sof skill & \multicolumn{2}{|c|}{ B: Superior/Excellent Performance } \\
\hline
\end{tabular}

Figure 22. Appraisal Report 
International Journal of Computer Science \& Information Technology (IJCSIT) Vol 6, No 4, August 2014

\subsection{Employee Master Data: Performance Criteria Setting}

Personal Detail: In this part of the application, HR admin will be able to maintain the basic employee information (Employee Detail, Position, Division, Nationality, Appraisers as can be seen in figures 23-26).

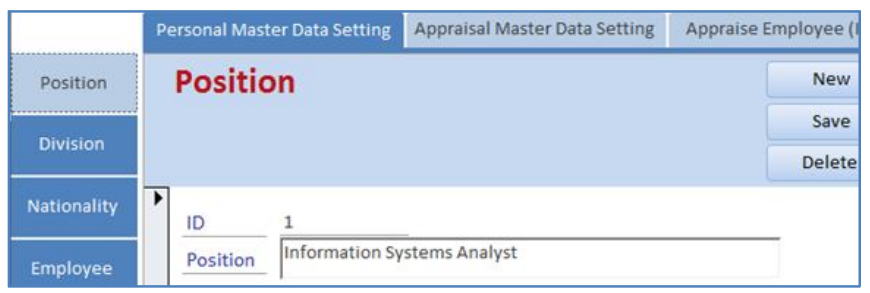

Figure 23. Position Detail

\begin{tabular}{|c|c|c|c|c|c|}
\hline & \multicolumn{2}{|c|}{ Personal Master Data Setting } & Appraisal Master Data Setting & Appraise Employee (Inputs) & Rules \\
\hline Position & \multirow{3}{*}{\multicolumn{2}{|c|}{ Division }} & & & New Division \\
\hline \multirow{2}{*}{ Division } & & & & & Save \\
\hline & & & & & Delete \\
\hline Nationality & \multicolumn{5}{|l|}{$\nabla$} \\
\hline Employee & Description & \multicolumn{4}{|c|}{ Information Systems \& Technology } \\
\hline
\end{tabular}

Figure 24. Division

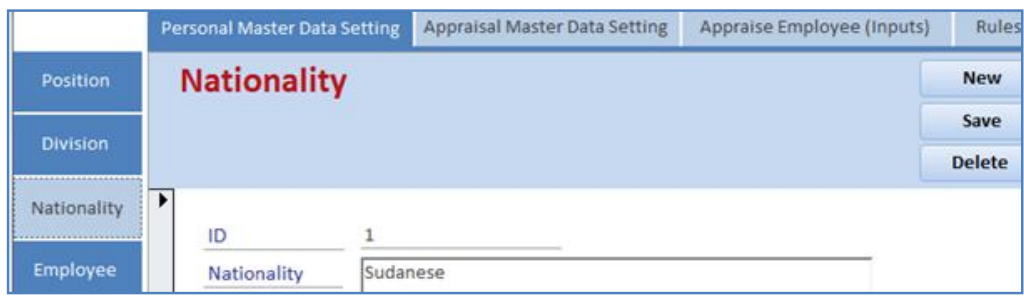

Figure 25. Nationality

\begin{tabular}{|c|c|c|c|c|}
\hline & Personal Master Data Setting & Appraisal Master Data Setting & Appraise Employee (Inputs) & Rules of \\
\hline Position & \multirow[t]{2}{*}{ Employee } & & & \\
\hline Division & & & & \\
\hline Nationality & Employee Number & 1234 & & \\
\hline \multirow[t]{6}{*}{ Employee } & Employee name & Ali Ali Ali & & \\
\hline & Division & Information Systems \& Techr & $\log y=$ & \\
\hline & Position & SAP PM Support Team Lead & - & \\
\hline & Entry date & $15 / 01 / 1995$ & & \\
\hline & Nationality & UAE & - & \\
\hline & Birth date & $13 / 01 / 1960$ & & \\
\hline
\end{tabular}

Figure 26. Employee Detail 


\section{FUTURE WORK}

Develop module to analysis the students' outputs using similarity measures such as Cosine similarity and max-min similarity measures. Also extend the system to use combination of more than one input.

\section{Conclusion}

This paper presented a fuzzy logic controller system for performance appraisal. The system has been implemented using MS Access database which was used to maintain the data, build the inference logic and develop all setting user interfaces.

The system is fully parameterized where the user will be able to select and change several parameters such as critical elements, fuzzy method and membership function.

\section{REFERENCES}

[1] L.A.Zadeh, "Fuzzy sets," Information and Control, vol.8, no.3, pp.338-353, June 1965.

[2] Adnan Shaout and Jaldip Trivedi, "Performance Appraisal System - Using a Multistage Fuzzy Architecture", International Journal of Computer and Information Technology (ISSN: 2279 - 0764) Volume 02- Issue 03, May 2013

[3] C.C.Yee, and Y.Y.Chen, "Performance Appraisal System using Multifactorial Evaluation Model", International Journal of Human and Social Sciences 5:12 2010

[4] Shruti S Jamsandekar, R.R Mudholkar, "Performance Evaluation by Fuzzy Inference Technique", International Journal of Soft Computing and Engineering (IJSCE) ISSN: 2231-2307, Volume-3, Issue-2, May 2013

[5] Nisha Macwan1, Dr.Priti Srinivas Sajja2, "Performance Appraisal using Fuzzy Evaluation Methodology", International Journal of Engineering and Innovative Technology (IJEIT) Volume 3, Issue 3, September 2013

[6] Amy H.I.Lee a, Wen-Chin Chen b,*, Ching-Jan Chang, "A fuzzy AHP and BSC approach for evaluating performance of IT department in the manufacturing industry in Taiwan ", Expert Systems with Applications 34 (2008) 96-107

[7] Rafikul Islama and Shuib bin Mohd Rasad b, "Employee performance evaluation by AHP: A case study", Asia Pacific Management Review (2006) 11(3), 163-176

[8] Adnan Shaout, Minwir Al-Shammari,"Fuzzy logic modelling for performance appraisal sysytems Aframework for empirical evaluation", Expert Systems with Applications 14 (1998) 323-328.

[9] E.H Mamadani and S. Assilian, "An experiment in linguistic synthesis with fuzzy logic controller", International Journal of Machine Studies, Vol. 7, No. 1, 1975. 